\title{
REFLEXIONES SOBRE ALGUNOS CONTENIDOS DE LA JUSTICIA PENAL ELECTORAL COSTARRICENSE*
}

\author{
Some reflections about Costarrican Electoral Criminal Justice
}

Andrei Cambronero Torres**

\begin{abstract}
Resumen: En una primera etapa, el artículo se avoca a delinear conceptualmente las locuciones "Justicia Penal Electoral" y "Delito Electoral", tomando como base la dogmática jurídico-penal tradicional pero, además, presentando particularidades propias de los actos relativos al sufragio. De otra parte, en temas específicos de la aplicación de la ley penal electoral, se sugieren -como ideas a tener en cuenta- elementos interpretativos que el operador jurídico penal debería valorar en este tipo de delincuencia.
\end{abstract}

Palabras clave: Delitos electorales - justicia penal electoral - delincuencia electoral procesos electorales - teoría del delito electoral.

Abstract: First, the article attempts to conceptually define the terms "electoral criminal justice" and "electoral crime", taking as a basis the traditional criminal-legal doctrine, in addition to presenting distinctions which are specific to suffrage. Furthermore, the article goes on to discuss specific issues concerning the enforcement of electoral criminal law and suggestions are made -as ideas to take into account- regarding interpretative elements that criminal legal authorities should consider in this type of crime.

Keyworks: Electoral crimes - electoral criminal justice - crime's theory - electoral process.

\footnotetext{
* El presente artículo se enmarca en la investigación "La Justicia Penal Electoral en Costa Rica" que, actualmente, el autor desarrolla como parte de los requisitos académicos para optar por el grado de Doctor en Derecho por la Universidad de Costa Rica (UCR).

** Abogado y Criminólogo. Profesor de la Facultad de Derecho de la UCR y Letrado del Tribunal Supremo de Elecciones de Costa Rica. Magíster en Justicia Constitucional y Licenciado en Derecho, ambos, por la UCR; Diploma de Especialización en Justicia Constitucional y Tutela Jurisdiccional de los Derechos, Universidad de Pisa, Italia. Bachiller en Ciencias Criminológicas por la UNED. Correo electrónico: andrei.cambronero@ucr.ac.cr.
}

Este artículo fue recibido el 18 de mayo de 2016, siendo aprobada su publicación el 21 de junio de 2016. 


\section{Introducción}

La Justicia Penal Electoral en Costa Rica es, como todo concepto, un marco dentro del cual puede incluirse -según las convenciones de los operadores- un variopinto de conductas, normas, doctrina y prácticas judiciales, entre otros. Precisamente, esa multivocidad impone a los usuarios de la alocución explicitar qué entienden por tal.

Para situarse en el pasado reciente, el Código Electoral costarricense (CEc) de 1953 (Ley n. ${ }^{\circ}$ 1536) tipificaba una serie de conductas como delito; el legislador había disvalorado, a través de la creación de tipos penales, actos lesivos relacionados con las diversas fases del proceso electoral. ${ }^{1}$ En efecto, en una redacción que entreveraba las contravenciones, delitos sancionados con multa $\mathrm{y}$ delitos castigados con prisión, la normativa de la segunda mitad del siglo $\mathrm{XX}^{2}$ presentaba uno de los elementos necesarios -mas no suficientes- de cualquier sistema penal: los tipos penales. ${ }^{3}$

De igual modo, la fijación de la competencia en los tribunales penales ordinarios para el juzgamiento de tales conductas ilícitas (artículo 154 de la referida legislación) y la ocurrencia, de hecho, de acciones que podían ser subsumidas por alguna de las formulaciones de los tipos objetivos, alcanzarían para reconocer la existencia de una "Justicia Penal Electoral en Costa Rica", al menos durante el período histórico nacional denominado "Segunda República".

Sin embargo, pese a la importancia de esos componentes, se considera que el objeto -concebido de esa manera- solo incorpora características formales. En otros términos, solo da cuenta de un diseño institucional capacitado para el juzgamiento de conductas ilícitas relacionadas con "lo electoral", mas no refiere al comportamiento real de los operadores frente al fenómeno de la "delincuencia electoral"; o sea, si los fiscales y jueces -por citar solo dos de los actores preponderantes del proceso penal- presentan un convencimiento de que esos actos son socialmente dañosos al punto de, realmente, merecer estar previstos en el derecho penal. ${ }^{4}$

\footnotetext{
${ }^{1}$ La Criminalización de conductas estaba centrada, básicamente, en los numerales 149 a 153 del citado Código Electoral hoy derogado.

2 Vigente además, con algunos cambios menores, durante casi toda la primera década del nuevo milenio.

${ }^{3}$ El principio de legalidad criminal, de extenso desarrollo en la doctrina, se puede presentar -en ajustada síntesis- con el aforismo latino "nulla poena sine lege" y constituye innegablemente un bastión del Derecho Penal democrático.

${ }^{4}$ Téngase presente la diferencia de lo real y el papel.
} 
De lo expuesto se sigue, como una de las premisas iniciales, que la presencia de un "organigrama funcional" e, incluso, ciertos procedimientos en la ley escrita no dan cuenta per se de la existencia fáctica del litigio penal electoral.

Uno de los síntomas de esa disparidad entre teoría y práctica judicial en el tema lo podemos extractar de Sobrado 5 quien señala: “... durante el período que va de 1988 al 2008 sólo se registran cuatro sentencias por delitos electorales y únicamente una de ellas es condenatoria". Precisamente en esa distorsión (law in books vs law in action) ${ }^{6}$ es en la que encuentra asidero uno de los puntos centrales de la presente reflexión.

El pensamiento normativista lleva, en términos generales, a un reduccionismo ingenuo o, como se ha señalado en otros espacios, a un simplismo jurídico; el aferrarse a la mitológica idea de la positivización normativa como panacea para los problemas sociales es, sin lugar a dudas, ingresar a una óptica para adquirir unas gafas de poco aumento (al menos menor al que se necesita). La tendencia a pensar que todo lo que el derecho prescribe sucede tal cual en la realidad nos coloca frente a la línea -cuando no nos lleva a cruzarla- de una de las manifestaciones de la magia verbal ${ }^{8}$ y nos distrae de los verdaderos embrollos o, más correctamente, de los problemas "en serio".

Por tal motivo, en aras de tener un acercamiento menos formalista, vale indicar que la vigencia fáctica? del Derecho Penal Electoral muestra una tendencia cercana a cero, pues pocos son los casos de este tipo denunciados al Ministerio Público y menos aún los que logran superar la etapa preparatoria. ${ }^{10}$ De ello, entonces, se pueden presumir -al menos- las siguientes circunstancias: a) la inexistencia de litigio en estos temas se debe a que no se cometen las conductas tipificadas en la norma penal; o, b) ciertamente ocurren las situaciones previstas en la norma mas, en la práctica, existen circunstancias que condicionan el ejercicio de la acción penal y dificultan que "lo electoral" en "lo penal" supere la fase intermedia del proceso.

Frente a los citados supuestos no se puede optar de manera maniquea por uno de ellos para explicar el fenómeno. Presumiblemente existirán algunas conductas previstas por el legislador que no lleguen a concretarse; en otros términos, pese a existir un delito cuyo contenido tipifique una acción específica, esta - por múltiples factores- tal vez jamás ocurra: el actual CEc sanciona de dos a

\footnotetext{
${ }^{5}$ SOBRAdO (2011), p. 248.

${ }^{6}$ Distinción de Pound desarrollada por Llewellyn que se sirve desarrollar HABA (2012, T.I, pp. 481-486).

${ }^{7}$ CAmbronero (2011).

8 Ver, entre otros, SALAS (2013), en especial capítulo "El sofisma de la magia verbal y del naturalismo lingüístico".

9 Albert (2007).

10 Más allá de la visión marcada por el "eficientismo penal" donde el "éxito" de la jurisdicción sancionatoria se mide en función del número de condenas.
} 
Cambronero - Reflexiones sobre algunos contenidos de la justicia penal electoral ...

seis años al funcionario electoral que, para incidir en la elección, modifique maliciosamente la lista de electores (numeral 278); sin embargo, en los tiempos que corren, la existencia de controles cruzados y el especial ánimo requerido para la configuración del tipo torna difícil el encontrarse un ilícito de estos en la realidad (supuesto " $a$ " mencionado en el párrafo anterior).

Empero, especiales factores como una construcción deficitaria en la gramática punitiva de las normas, ${ }^{11}$ la ausencia de regulación sobre el particular y, en especial, una cultura jurídica ${ }^{12}$ reacia a introducir dentro de los juegos del lenguaje ${ }^{13}$ del Derecho Penal los ilícitos relacionados con los actos del sufragio favorecen, según nuestra presunción, a la dificultad para perseguir este tipo de conductas. Si quien ostenta primacía en el ejercicio de la acción penal no concibe como trascendente una determinada conducta, no la perseguirá o, al menos, no lo hará con el debido empeño (presunción " $b$ " expuesta en el párrafo tras anterior).

Un breve paréntesis aclaratorio. Si bien habrá podido notarse que, como punto de partida, se afirma la intersubjetividad de los agentes del sistema penal para entender la delincuencia electoral como un tema de poca monta, lo cierto es que la persecución de ilícitos relacionados con el financiamiento de campañas electorales constituye una excepción: la presión social (catalizada por los mass media), la evolución de estudios acerca de corrupción en estos espacios ${ }^{14} \mathrm{y}$ toma de esas campañas por agentes con fines espurios en la región latinoamericana han llevado a que actores relevantes del proceso penal tomen decisiones para su efectivo juzgamiento. ${ }^{15}$

Ahora bien, otra de las manifestaciones tipo b) viene dada porque, en apariencia, los locutores de la disciplina penal no hallan un "parecido de familia"16 entre los topoi aglutinados bajo el paraguas "teoría del delito" (TDD) y los propios del ámbito electoral, con lo que se descarta la interacción entre las categorías y la posibilidad de analizar una conducta suscitada en una dinámica propia del proceso electoral desde conceptos jurídico-penales tradicionales se torna compleja.

\footnotetext{
11 SOBRADO (2011) les llama “errores de tipificación penal”, p. 248.

12 Se entiende cultura jurídica como la actitud y valoraciones (compartidas) de los operadores del sistema hacia determinado objeto de relevancia jurídica, sea previsto en alguna norma de esa clase. 13 WiTTGENSTEIN (2012).

${ }^{14}$ Ver entre otros, Fundación Konrad Adenauer (2010), CASAS y ZOVATTO (2011) y DE LA CALLE (2011).

15 La Fiscalía General de la República de Costa Rica, en ejercicio de su atribución para fijar la política de persecución penal -artículo 25 de la ley orgánica de ese órgano-, emitió la circular n. ${ }^{\circ}$ 01-PPP-2013, por intermedio de la cual se reconoce que, tratándose de la antijuridicidad formal (lesión al bien jurídico), cualquier conducta relacionada con financiamiento partidario debe ser perseguida.

${ }^{16}$ WiTTGENSTEIN (1999).
} 
Sin perjuicio de lo indicado no se considera que existan disputas "insalvables" o algo similar a una inconmensurabilidad local ${ }^{17}$ entre lo electoral y lo penal que impida tender puentes para lograr, en la práctica, la existencia de una Justicia Penal Electoral; mas, ciertamente, es necesaria una reconfiguración de los contenidos conceptuales que durante largo tiempo se han dado a los componentes de la TDD.

En ese sentido más allá de una visión formalista se sugiere tener a la Justicia Penal Electoral en una dimensión material: incorporación no solo de los componentes normativos, sino también de las dinámicas sociales intra y extra proceso judicial; o sea, además de una política criminal en lo electoral el entramado institucional para la persecución y juzgamiento de las conductas y el diseño propio de la jurisdicción (normas sustantivas y procesales) es trascendental mirar integralmente las prácticas de los participantes del proceso. El análisis no se agota en el repaso de la asignación formal de competencias a los diversos protagonistas del juicio, sino en la revisión de esos aspectos más las prácticas concretas de valoración que realizan los actores frente a un hecho específico.

Comúnmente la doctrina especializada referencia la Justicia Penal Electoral como el conjunto de instituciones dispuestas para sancionar una conducta contraria a los principios democráticos relacionados con la elección de autoridades, así como el rol desempeñado por cada uno de los partícipes en esos procesos $;{ }^{18} \sin$ embargo, se deja por fuera cuáles son los aspectos particulares para tener en consideración al momento de aplicar una matriz teórica (la TDD) a una conducta humana lesiva -o peligrosa- acaecida en el terreno de lo electoral.

Desde esa perspectiva baste decir -para complementar lo señalado en las primeras líneas- que la Justicia Penal Electoral es un fenómeno jurídico-cultural comprensivo donde se incluyen las reglas del juego -previsiones normativas-, cómo han sido interpretadas normalmente esas pautas, los comportamientos sociales concretos y las guías de aplicación de la dogmática penal a un campo criminal sui generis.

Con base en esa lógica el presente artículo pretende mostrar cómo, en algunos aspectos generales de la dogmática penal, podrían tomarse en cuenta especificidades de "lo electoral" en aras de lograr una verdadera vigencia pragmática de la Justicia Penal Electoral.

\footnotetext{
${ }^{17}$ KUHN (1989).

18 Entre otros, BETANZOS (2012) y DíAz (2013).
} 
Cambronero - Reflexiones sobre algunos contenidos de la justicia penal electoral ...

\section{Delito electoral}

Como uno de los componentes principales de esta particular dinámica punitiva, resulta pertinente clarificar qué hemos de entender por "delito electoral". Si bien la unidad básica del derecho sancionatorio es la descripción de una conducta (o falta de ella en los casos omisivos) a la cual el legislador le atribuye un castigo que, tratándose del Derecho Penal, es la privación de la libertad o una multa (nos referimos al tipo), lo cierto es que esa construcción gramatical es insuficiente para calificar un determinado comportamiento como delito.

En concreto debe resaltarse la diferenciación entre tipo y delito pues, a lo sumo, la sinonimia de ambos términos puede darse en el plano formal. Como lo señala Muñoz Conde: "El concepto de delito como conducta castigada por la ley con una pena es, sin embargo, un concepto puramente formal que nada dice sobre los elementos que debe tener esa conducta para ser castigada por la ley"." Desde esa perspectiva hacer un ligamen directo entre la proposición legal y el "delito" resulta un reduccionismo que poco aporta a una comprensión pragmática de la cuestión. ${ }^{20}$

La existencia de una TDD supone, en palabras de Bacigalupo, ${ }^{21}$ que este es "una descomposición [de la conducta] en un sistema de categorias jurídicas que facilitan la aplicación de la ley penal por parte de los tribunales." En otros términos, el delito como tal, es una construcción teórica basada en una acción humana jurídicamente relevante (iimportancia normativamente asignada!) cuyo encuadre en estratos analíticos $^{22}$ (jconsensuados e igualmente teóricos!) es necesario para la imposición de la pena prevista en la formulación legal.

De otra parte, Zaffaroni ${ }^{23}$ atribuye el calificativo de "ente jurídico" al delito. ${ }^{24} \mathrm{Si}$ bien el autor prima la necesaria positivización de una conducta en la ley penal como sustrato de tal concepto (con lo que se quedaría en el plano formal), lo cierto es que conjuga otros factores dogmáticos para dar contenido a la

\footnotetext{
19 MuÑoZ CONDE (1984), p. 2.

${ }^{20}$ Sobre este punto ZAFFARONI (1998), pp. 11-12, t.III distingue entre delito lato sensu y delito stricto sensu; entendiendo la primera acepción como la conducta típica a la que le "hacen faltan" la antijuridicidad y la culpabilidad.

${ }^{21}$ BACIGALUPO (1994), p. 37.

${ }^{22}$ Nos referimos a tipicidad, antijuridicidad y culpabilidad como componentes de la TDD.

23 ZAFFARONI (1998).

${ }^{24} \mathrm{El}$ autor clarifica la no indeterminación absoluta del concepto en el tanto lo ontologiza. Se afirma que el conocimiento no crea el objeto (en este caso el delito), con lo que podría ubicarse tal posicionamiento teórico más hacia el extremo "racionalista" de la pregunta cómo se conoce, hipótesis que se alimenta con sus alusiones a reglas lógicas en la construcción de la dogmática penal, tales como la no contradicción y el uso del método deductivo para "reducir" la abstracción de la formulación normativa (tipo penal) a una situación concreta. Por último, el jurista argentino acerca la dogmática penal a la física, dejando entrever una inclinación -al menos inicial- al positivismo cognitivo (más preciso: propende a una clase de monismo metodológico).
} 
formulación: su amplio desarrollo acerca de los componentes de la enunciada teoría permiten concluir que su concepción, al igual que la doctrina citada en los párrafos precedentes, es favorable al reconocimiento del delito como algo más complejo que varias oraciones formando una norma punitiva.

En suma, la doctrina penal es coincidente en describir el delito como una construcción teórica, ${ }^{25}$ sea una conducta imputable a un sujeto que cumple con unas características fijadas por la comunidad epistémica en una suerte de test de verificabilidad (TDD).

Sin embargo, al cruzar la acera, la situación es un tanto diferente. Tratándose de la doctrina electoral especializada el péndulo tiende a ubicarse en el centro: lejos de una tendencia predominante en la que se tenga al delito como el resultado de un ejercicio analítico -a partir de categorías conceptuales predefinidas según acuerdos mayoritarios entre los locutores de la disciplina- la tendencia es a constituir una formulación en la que destacan tres componentes relacionados entre sí: a) conducta lesiva; b) principios electorales; y, c) definición y sanción en una norma de rango legal.

En efecto, si se consultan fuentes doctrinarias tradicionales como el "Tratado de derecho electoral comparado de América Latina" (2007) -que a su vez referencia el Diccionario Electoral de CAPEL (2000)-, es fácilmente observable la homologación del concepto "delito electoral" con una conducta disvalorada por la ley cuya comisión debe castigarse al haber falseado aspiraciones (componente axiológico) del sistema político republicano. Puntualmente el citado diccionario define ese concepto como "conductas, acciones, incluso omisiones atentatorias contra los principios que han de regir un sistema electoral en un Estado democrático y que por su propio carácter peculiar, son definidas y castigadas [...] en la propia ley electoral.".

Las producciones dogmáticas mexicanas y españolas, coincidentes además con la definición antes transcrita, resuelven el contenido del término circunscribiéndolo a una afectación (por acción u omisión) de las diversas fases del proceso electoral, sus actores o los postulados básicos que, sobre el sufragio, pregona el ideal democrático. ${ }^{27}$

Ciertamente se han intentado definiciones un poco más exhaustivas como la del propio Zamora ${ }^{28}$ quien entiende al delito electoral como "bipótesis legislativas que suponen comportamientos bumanos determinados, que solamente pueden realizarse durante

\footnotetext{
25 Adicionalmente, puede notarse tal concepción en los a priori de los que parten ROXIN, JAKOBS, SCHÜNERMANN, FRISCH y KÖHLER, entre otros, (2000) y en sus producciones en general.

${ }^{26}$ En similar sentido AHUATZi (2002), MARTíneZ (2003) y PlASCENCIA (2010).

27 Betanzos (2012), Cruz (2013), GÁlvez y Rubio (2007), MuÑoz CONDE (1983), OrTs (1977)

y ZAMORA (2003).

${ }^{28}$ ZAMORA (2003), p. 71.
} 
Cambronero - Reflexiones sobre algunos contenidos de la justicia penal electoral ...

los tiempos en que los organismos electorales determinan formalmente el inicio del proceso correspondiente, que también tendrá una etapa de culminación por lo que un delito de esta naturaleza podrá cometerse a través de una conducta que acontezca hasta en tanto se agote el último de los recursos y asuman los cargos a que fueron electos los candidatos."

Sin embargo pese a no existir inconveniente con acepción formal de "delito electoral" ${ }^{29}$ lo cierto es que tal definición es insuficiente. Como hipótesis de trabajo sostenemos un carácter sui generis en la delincuencia electoral como justificante para la aplicación de una TDD diferenciada (con componentes que, en su valoración, tomen en cuenta las especificidades del fenómeno electoral); de esa suerte, si se admitiera de entrada, una conceptualización de la unidad base -el delito- deslindada de los aspectos sustanciales se negaría ab initio la referida especialidad (jcontradicción!), pues no se demarcaría ese carácter propio del fenómeno electoral que lo distancia de, por ejemplo, los delitos comunes.

De esa forma debe plantearse un concepto ecléctico en el que se complementen los aspectos formales con la concepción material de la dogmática penal tradicional -esto es privilegiar el carácter de resultado analítico- y además se tomen en cuenta las particularidades del fenómeno electoral. Precisamente en esa tarea de construcción si a la categoría "delito" le hemos de asignar el calificativo de "electoral" procede definir, entonces, este último vocablo como paso previo.

Al no ser el tema central del presente estudio no resulta pertinente entrar en valoraciones acerca de la evolución que, principalmente en la jurisprudencia del Tribunal Supremo de Elecciones de Costa Rica (TSE) y en la doctrina especializada, ha tenido la respuesta a la pregunta ¿qué es lo "electoral"? 30 Baste indicar que se entenderán como parte de ese fenómeno "todos los actos relativos al sufragio, asi como las normas y demás actos sujetos al Derecho Público que regulen y desarrollen el derecho a la participación politica, las que establezcan mecanismos de protección para su efectivo goce o reparación y las destinadas a regular la conformación y atribuciones del Tribunal Supremo de Elecciones".

Ahora bien, conjuntando lo anterior con una perspectiva material, proponemos, como concepto que el delito electoral en Costa Rica es una acción típica,

\footnotetext{
29 Entiéndase por definición formal toda aquella proposición similar a la siguiente: previsión normativa que prevé una sanción penal para una conducta lesiva a componentes del sistema electoral.

30 Sobre este punto pueden consultarse, entre otros, los estudios de BRENES (2013 y 2002),

CAMBRONERO y MORA (2015) y SOBRADO (2012 y 2005).

${ }^{31}$ CAMbronero y MORA (2015), p. 182.
} 
antijurídica y culpable, ${ }^{32}$ en la cual el tipo objetivo aspira a la protección de un interés o bien jurídico intimamente relacionado con el objeto electoral.

Importante enfatizar en ese último aspecto. No solo es necesaria la existencia de una acción lesiva, sino que esta debe corresponderse con una tipificación favorable a la tutela de un aspecto de relevancia electoral (ipunto medular!). Asimismo, aunque parezca una trivialidad indicarlo, para una adecuada calificación del comportamiento en los términos expuestos debe evitarse la "trampa de contexto" (mostrar una actitud irreflexiva en la que toda conducta dañosa de relevancia jurídico penal es calificada como delito electoral por el hecho de haberse producido en eventos propios del proceso comicial).

Para una mejor comprensión, dos ejemplos. El militante de un partido político, aprovechando la algarabía de una plaza pública, golpea -con el asta de su bandera- a otro de los participantes (un sujeto con quien tenía desavenencias) y, producto de esa acción, la víctima fue incapacitada por seis días. En este caso no podría calificarse la conducta como un delito electoral pues, como resulta obvio, desde el criterio formal no puede encuadrarse la conducta en ninguno de los tipos penales del capítulo I, título VI del CEc pero, desde el concepto propuesto, la norma penal que criminaliza tal conducta (lesiones leves) ${ }^{33}$ no tutela ningún bien jurídico de relevancia electoral con lo que se descarta de la categoría "delito electoral" también por esta circunstancia.

Véase un cuadro fáctico menos claro. El ciudadano A es el miembro presidente de una junta receptora de votos (JRV), en la madrugada del día de la elección su esposa lo encierra en el cuarto y, producto de ello, no puede desempeñar su cargo. Esa situación obliga a integrar el organismo electoral con los auxiliares electorales. Según lo descrito, la esposa de "A" debe ser acusada por impedir que uno de los integrantes de una JRV cumpla con sus funciones ${ }^{34} \mathrm{O}$, en su defecto, por una privación de libertad. ${ }^{35}$

Frente a ese cuestionamiento es imperioso realizar un análisis del ánimo de la esposa de "A": cuál fue el motivo que la llevó a encerrar a su cónyuge. Si se logra determinar que impidió la salida de su marido con el fin de evitar la constitución de la JRV y entorpecer el proceso de votación entonces podría resultar aplicable el tipo del inciso c) del ordinal 272 del CEc, ya que con su acción

\footnotetext{
32 Hasta este punto la definición es similar a la de BARRIOS (2009), empero este autor omite referenciar qué considera como "acción electoral" y no evoca mayores precisiones en cuanto a los alcances y límites de ella.

${ }^{33}$ El Código Penal de Costa Rica, en su ordinal 125, señala: "Se impondrá prisión de tres meses a un año a quien causare a otro un daño en el cuerpo o la salud, que determine incapacidad para sus labores habituales por más de cinco días y hasta por un mes.".

${ }^{34}$ Delito electoral previsto en el inciso c) del numeral 272 del CEc.

${ }^{35}$ Delito ordinario contemplado en el artículo 191 del Código Penal costarricense.
} 
Cambronero - Reflexiones sobre algunos contenidos de la justicia penal electoral ...

-suponiendo la existencia del resto de componentes de la TDD- encuadra en una descripción normativa prevista para castigar la afectación del adecuado desarrollo de la jornada electoral. Por el contrario, si el encierro de A se debió a una disputa marital procedería la persecución penal por privación de libertad.

Como puede concluirse de las valoraciones descritas en el párrafo anterior se configura un concurso aparente de normas que es necesario resolver en el caso concreto; no obstante el punto por ilustrar acá es que el contexto comicial no puede tomarse, sin más, como un criterio decisivo para calificar una conducta como delito electoral. ${ }^{36}$

Por último de la definición dada párrafos atrás conviene explicitar los alcances de los componentes temporal y material del objeto electoral en el espacio sancionatorio. Acerca de la materia, para el caso costarricense, en los actos relativos al sufragio se encuentran contenidos -además- aquellos propios de una consulta popular de alcance nacional; en otras palabras, las figuras delictivas acerca del referéndum deben entenderse incluidas en el calificativo "electoral". En efecto de manera expresa - en la Ley de Regulación del Referéndum- el legislador admitió que las conductas descritas en los tipos penales electorales pueden cometerse durante (o con ocasión de) un proceso electoral de carácter consultivo (artículo 32). ${ }^{37}$

Acerca del componente temporal, como se habrá percibido no hay mención alguna a este en la definición propia sugerida párrafos antes. Esa actitud silente es consciente y voluntaria: en el sistema nacional no pueden establecerse fechas entre las cuales es posible la comisión de delitos electorales; en otros términos, contrario a lo establecido por Zamora ${ }^{38}$ no es dable un "criterio del calendario" para confirmar o descartar la ocurrencia de una acción lesiva de tal naturaleza.

Una revisión rápida de la legislación penal electoral costarricense basta para comprender que hay acciones típicas cuya comisión puede darse en cualquier tiempo. Así por ejemplo: la alteración del padrón, la recepción de donaciones o aportes prohibidos y la renuencia a publicar resoluciones del TSE en el Diario Oficial son situaciones que pueden suscitarse a lo largo del ciclo electoral y no solo entre el lapso que va desde la convocatoria a la elección hasta la toma de posesión de las autoridades electas, como pretende Zamora.

\footnotetext{
36 CRUZ (2013) ofrece una clasificación inicial que diferencia los "delitos exclusivamente electorales" de los "delitos comunes cometidos en el ámbito electoral"; sin embargo, esa diferenciación es útil en el ámbito español por la forma en la que están tipificadas las conductas. En el sistema costarricense, tal separación no resulta pertinente pues, como se indicó, las paradojas entre los tipos ordinarios y los electorales se constituyen en concursos aparentes.

${ }^{37}$ Sobre la legitimidad de esta norma que podría considerarse un "tipo penal general en blanco".

${ }^{38}$ ZAMORA (2003), p. 71.
} 
Por tales motivos y para concluir el presente apartado se descarta categóricamente el componente temporal como parte del concepto de "delito electoral", pese a existir acciones típicas que solamente se dan en momentos específicos como el día de la elección. ${ }^{39}$

\section{Aplicación de la ley penal electoral en el espacio}

El ejercicio del poder punitivo supone una prerrogativa reglada del Estado: el aparato institucional es, en principio, el único legitimado para castigar conductas contrarias a las pautas sociales de convivencia. En términos contractualistas diríamos: corresponde al aparato público exclusiva y excluyentemente reprimir las acciones contrarias al pacto social.

En los sistemas republicanos debe existir una criminalización primaria previa en sede legislativa como elemento necesario para el ejercicio de tales prerrogativas; empero la promulgación de leyes penales no supone la universalidad de su aplicación. En efecto en los planos formal y material se suscitan valladares para la implementación de esas normas.

Una de esas delimitaciones, quizás la más obvia, es la territorial. La ley penal al ser un ejercicio de soberanía, ${ }^{40}$ se encuentra acotada - por regla general- al país: los tipos penales son aplicables a aquellas acciones u omisiones llevadas a cabo en el territorio nacional. ${ }^{41}$

Ahora bien en el lenguaje forense el lugar de comisión de un hecho punible puede adquirir varios matices: a) por una parte el legislador puede optar por referirlo al sitio donde se llevó a cabo la acción; b) puede apuntar a la locación donde se produjo el resultado; y c) puede aludir a ambos escenarios: el de la acción y el del resultado.

Precisamente Costa Rica se adscribe al último supuesto ya que, en razón de la previsión del numeral 20 de su Código Penal, "el hecho se considera cometido en el lugar en que se desarrolló, en todo o en parte, la actividad delictuosa y en el lugar en que se produjo o debió producirse el resultado." Por ello, Castillo ${ }^{42}$ afirma la teoría de la ubicuidad como la propia de nuestro régimen penal: el código -para fijar el lugar

\footnotetext{
${ }^{39}$ Ver, por ejemplo, los tipos penales de los artículos 271 y 272 del CEc.

40 Castillo (2008) y Bacigalupo (1994).

${ }^{41}$ Para fines jurídico-penales, a partir de una lectura ligada de los artículos 6 de la Constitución Política costarricense y 4 del Código Penal, se considera territorio: el espacio geográfico de 51100 $\mathrm{km}^{2}$, el espacio aéreo, el mar territorial, el zócalo insular, la plataforma continental y las naves y aeronaves de bandera nacional, CASTILLO (2008), pp. 154-155, t. I).

${ }^{42}$ CAstillo (2008), p. 158 t. I.
} 
Cambronero - Reflexiones sobre algunos contenidos de la justicia penal electoral ...

del hecho punible- "toma en cuenta tanto el desvalor de la acción como el desvalor del resultado."

Lo anterior es importante tratándose de los delitos electorales. Una de las innovaciones del CEc de 2009 fue la inclusión del voto en el extranjero: a partir de la elección presidencial de 2014 los costarricenses domiciliados allende las fronteras del país -y que hubieran tramitado su cambio de domicilio electoralpueden participar en las votaciones presidenciales y en las consultas populares de alcance nacional, ${ }^{43}$ mediante el ejercicio del sufragio en los diversos consulados de Costa Rica alrededor del mundo. Sin embargo aparejado a ese avance en los derechos políticos de quienes se ven obligados a abandonar el territorio por razones laborales, familiares o académicas los espacios para la ocurrencia de hechos ilícitos también se diversificaron.

La instalación de juntas receptoras de votos en las sedes consulares genera las condiciones para que, de hecho, se den ilícitos electorales fuera del país; ciertamente la posibilidad de realizar actos jurídicamente reprochables desde fuera de las fronteras nacionales ha estado presente incluso antes de la promulgación del actual CEc: por ejemplo, las irregularidades con ocasión del financiamiento de campañas electorales pueden suscitarse con donaciones o aportes desde el extranjero sin que para ello se requiera, como elemento necesario, la instalación de JRV en el extranjero.

Sin embargo de un repaso de la legislación penal-electoral anterior (nos referimos al CEc derogado en 2009 con la entrada en vigencia de la nueva legislación) es fácilmente observable como los tipos tenían un marcado acento en la criminalización de conductas suscitadas durante el lapso de campaña y el propio día de la elección (concretamente en las JRV) lo que, por no existir voto fuera del país, no presentaba mayores cuestionamientos en cuanto al espacio de aplicación de la norma punitiva.

En el nuevo paradigma sí es dable que un ciudadano vote dos veces, suplante a un fiscal, retenga documentación electoral o -cual donación en especiefacilite un local para llevar actividades proselitistas en Pekín, Viena, Roma, Santiago o Buenos Aires, por citar algunos sitios en los que Costa Rica tiene habilitados consultados. De esa suerte, cabe preguntarse si es viable, a partir de las reglas tradicionales y la reflexión dogmática al respecto, procesar a un sujeto radicado desde hace varias décadas en Austin por impedir el adecuado funcionamiento de la junta receptora del consulado de Chicago.

\footnotetext{
${ }^{43}$ Ver artículos 187 a 192 del C.E. y el decreto del TSE n. ${ }^{\circ}$ 4-2013, "Reglamento para el ejercicio del voto en el extranjero".
} 
Pero, previo a realizar tal análisis, una advertencia. Es evidente que el estudio acerca de la aplicación de la ley penal en el espacio debe darse en el plano concreto; sea frente a un caso particular el operador jurídico es quien realiza una evaluación de las circunstancias y define la procedencia o no de utilizar el marco sancionatorio patrio. Ese ejercicio se realiza a través de los criterios definidos $-\mathrm{y}$ de sobra conocidos- en la doctrina penal. ${ }^{44}$

En efecto la territorialidad, la defensa, la justicia universal, la personalidad activa, la personalidad pasiva, la universalidad o el juzgamiento por representación son las pautas orientadoras para precisar si una conducta llevada a cabo en un sitio determinado puede ser juzgada según la ley penal de otro país específico.

Sin demérito de ello no es estéril la empresa de proponer como guía a través de cuál de los mencionados criterios podría, un tribunal interno, conocer de ilícitos electorales cometidos en el extranjero. Véase que, así formulado, implícitamente se está descartando la territorialidad en cualquiera de sus dimensiones, con lo que la referencia realizada a la teoría de la ubicuidad pareciera fútil.

No obstante esa alusión deviene necesaria a fin de descartar la territorialidad de forma contundente y no solo sugerida. Al considerarse "lugar de los hechos" no solo la localidad donde ocurre la acción sino también el resultado, es fundamental dejar claro que aun así las acciones llevadas a cabo en el extranjero -principalmente tratándose de los tipos sobre el funcionamiento de las juntas electorales y los relativos al financiamiento partidario- no tienen las características idóneas para encuadrar en el criterio referido al territorio.

Para continuar con el ejemplo enunciado párrafos atrás alguien podría pensar que sufragar más de una vez en la misma elección -en una junta del extranjero- tiene efectos sobre el país: una afectación al cómputo final de votos recibidos por las agrupaciones políticas que, a su vez, sirve de base a la declaratoria de elección realizada por el TSE. En ese tanto, prima facie parecería plausible aducir la ubicuidad como base para legitimar la aplicación de la ley penal al elector.

Empero esa postura lleva consigo el reconocimiento de la citada acción dañosa como una de resultado siendo, antes bien, una de mera actividad. Más allá de si el doble voto de un sujeto incide o no en quién ha de ser declarado electo para desempeñar un cargo, ${ }^{45}$ lo disvalorado es la acción: sufragar más de una vez. Por tal motivo se concluye el agotamiento del delito en tierras foráneas, sin que

\footnotetext{
${ }^{44}$ Sobre el contenido de tales criterios pueden consultarse, entre otros, CASTILLO (2008), t. I, pp. 148 y ss., ZAFFARONI (1998) t. I, pp. 256 y ss., BACIGALUPO (1996), pp. 47 y ss. y CREUS (1992), pp. 110 y ss.

${ }^{45}$ Evidentemente, esto es una hipótesis posible pero improbable.
} 
Cambronero - Reflexiones sobre algunos contenidos de la justicia penal electoral ...

pueda considerarse ese eventual resultado como suficiente para acreditar un nexo con el territorio y, así, aplicar la teoría de la ubicuidad.

En similar sentido opera con los delitos acerca del financiamiento partidario. Supóngase que en otro país un extranjero dona algunas horas de perifoneo a una agrupación política para que - a través de ese servicio- realice propaganda en una de las localidades de mayor concentración de costarricenses con el afán de obtener una votación mayor; ${ }^{46}$ en esa hipótesis podría estarse ante una transgresión del numeral 274 inciso a) -sancionada de dos a cuatro años de prisión- y podría decirse que la ley penal costarricense es aplicable en el tanto el beneficio antijurídico lo recibe un partido político nacional que, eventualmente, verá aumentado su caudal de votos por la donación cuestionada (resultado en el territorio de Costa Rica). Mas nuevamente se estaría extendiendo demasiado el nexo entre la conducta y una consecuencia posible (beneficio a la agrupación receptora en el país) en aras de aplicar el referido principio de territorialidad; postura por lo demás forzada.

Frente a ello se considera que el principio más adecuado para justificar la aplicación de la ley penal costarricense a los ilícitos electorales ocurridos allende de las fronteras es el "Real o de Defensa". Castillo (2008:162-163) señala que este principio de protección "extiende el ámbito de validez de la ley penal a hechos cometidos fuera del territorio nacional que lesionan o ponen en peligro intereses o bienes jurídicos nacionales.”.

Precisamente, para aclarar la connotación de "bienes jurídicos nacionales" se puede recurrir a la definición que, sobre este principio, hace Bacigalupo, ${ }^{47}$ pues "refiere a la protección de bienes jurídicos del propio Estado y que afectan a su integridad como tal (orden público, traición a la patria, moneda y documentos nacionales, etc.)."

Sobre esa línea el citado autor costarricense divide en tres grandes grupos los ilícitos que justificarían la aplicación de la ley patria en aras de proteger los intereses supraindividuales del país: a) acciones contra la seguridad interior y exterior del Estado; b) conductas contra la economía de la nación; y c) actos en perjuicio de la Administración Pública cometidos por funcionarios -nacionales o extranjeros- a su servicio. ${ }^{48}$

Es fácilmente observable como los supuestos por encuadrar en las categorías a) y b) resultan ajenos a la delincuencia electoral; empero tratándose de

\footnotetext{
46 Igualmente válido para ilustrar la situación, es el ejemplo de facilitar un inmueble para que un partido político instale un local, entre otras donaciones en especie.

${ }^{47}$ BACIGALUPO (1996), p. 51.

${ }^{48}$ Esa tripartición el autor la desarrolla a partir de una separación de los supuestos del artículo 5 del Código Penal.

${ }^{49}$ CASTILlo (2008).
} 
los delitos contra la seguridad del Estado existe una porosidad en el estrato que permite incluir, según nuestra perspectiva, los tipos penales previstos en el Código Electoral cuando son cometidos en el extranjero.

Para dar luz a la formulación "acciones contra la seguridad interna y externa del Estado" 50 detalla una lista de títulos del Código Penal costarricense en los que, según su análisis, se encuentran tipos tendientes a la protección de tales intereses, mas reconoce la imposibilidad de limitar el concepto a esos delitos pues la propia legislación es omisa en el tema dándose cabida a la interpretación.

Puntualmente el referido jurista señala: "debe considerarse que el concepto de "delitos que atenten contra la seguridad interior o exterior del Estado" no es un concepto que se encuentre definido en el código penal. Por consiguiente, es un concepto sujeto a interpretación. ${ }^{\prime 51}$

De acuerdo con lo anterior puede considerarse la aplicación de la ley penal costarricense a hechos punibles cometidos en el extranjero en aras de hacer una "protección racional de los intereses estatales" 52 sin que necesariamente las figuras típicas sean las previstas en los títulos IX, X, XI, XII y XIII del citado código sancionatorio.

Ahora bien la estabilidad política de un determinado Estado depende en gran medida de las transiciones pacíficas del poder. La aceptación de los resultados electorales por parte de los actores políticos de peso permite a su vez y, como proceso mutuamente condicionante, la consolidación institucional en un determinado país. Esas circunstancias en el juego democrático son fraguadas al calor de un proceso legitimador: las elecciones.

Consecuentemente la confiabilidad en el sistema electoral y su virtud para crear empatía ${ }^{53}$ con quienes realmente cuentan en la competencia por el poder, son rasgos ineludibles para la estabilidad interna de la nación. ${ }^{54}$ Para Mora y Fernández ${ }^{55}$ el proceso electoral en sí mismo y la existencia de un órgano independiente, permanente, especializado e imparcial (luego de 1948) han sido dos de los factores determinantes en la estabilidad democrática de Costa Rica.

\footnotetext{
50 Ibid., p. 164.

${ }^{51}$ Ibid.

${ }^{52}$ Ibid.

53 Elementos a tomar en consideración a la hora de decidir en la clásica interrogante: ¿bullets or ballots?

54 Sobre este tópico puede consultarse el estudio de DíAz (2010) relacionado con las reglas electorales y la estabilidad política de Costa Rica.

55 MORA (2010); FERNÁNDEZ (2006).
} 
Cambronero - Reflexiones sobre algunos contenidos de la justicia penal electoral ...

Aunado a ello el controvertido resultado electoral de 1948, la coyuntura política de esa época y la cuestionable administración de los procesos electivos -como tónica de los comicios de la segunda mitad del siglo XIX y primer fragmento del siglo XX- fueron parte de los detonantes para la ruptura del orden constitucional en ese año provocándose una inestabilidad interna. ${ }^{56}$

Desde esa inteligencia la pureza del sufragio (junto con el constructo institucional a su servicio) supone un elemento necesario para la estabilidad interior del Estado, siendo de interés general perseguir su lesión -o puesta en peligro- aun cuando las acciones hayan sido cometidas fuera del espacio territorial de la república.

En términos generales la pureza del sufragio es el bien jurídico protegido por los ilícitos electorales comportándose este como un concepto abstracto y colectivo favorable a la normalización de las relaciones sociopolíticas a lo interno de un sistema determinado; en ese tanto, la aplicación de la ley penal nacional se yergue como un mecanismo idóneo para la protección racional de intereses estatales característica esencial sugerida por la doctrina para admitir la enunciación del principio real o de defensa.

En breve: al proteger los delitos electorales un interés colectivo con incidencia sobre la estabilidad del sistema político (un componente de la seguridad interna del Estado) es admisible subsumir en ellos conductas llevadas a cabo en el extranjero (independientemente de la nacionalidad de su autor) a través del sobradamente citado criterio de protección.

De otra parte al no ser necesaria la doble incriminación se refuerza la aplicabilidad del criterio. Este tipo de delincuencia, al ir ligada al componente sociológico de la dinámica política de un determinado conglomerado social, suele tener particularidades normalmente no replicables en otros sistemas, ${ }^{57}$ con lo que exigir tipos -concurrentes en el país de comisión y en el Estado en el que se ejercería el poder punitivo- podría ser un óbice para el efectivo juzgamiento.

Sin embargo en el principio de defensa ese inconveniente no se presenta pues "tampoco se requiere el principio de la doble incriminación en los casos que entran bajo el principio real o de defensa [...] puesto que un delito contra la seguridad interior o exterior del Estado costarricense [...] no es punible conforme al derecho penal del Estado extranjero, que no puede defender bienes jurídicos cuya defensa corresponde solamente al Estado costarricense.

\footnotetext{
${ }^{56}$ Sobre estos temas pueden verse las obras de LEHOUCQ (1993) y de MOLINA y LEHOUCQ (1999).

${ }^{57}$ Piénsese en figuras propias de la delincuencia electoral mexicana como las mencionadas páginas atrás: operación tamal, juego del gato y el ratón, etc.

${ }^{58}$ CASTILlo (2008), p. 165
} 
Con base en lo expuesto se concluye que, tratándose de ilícitos electorales, se deben observar los principios tradicionales de "aplicación de la ley penal en el espacio" y, en concreto, para los casos de conductas reprochables cometidas en el extranjero con ocasión de un proceso electoral, el Estado costarricense puede -lícitamente- aplicar su derecho sancionatorio en razón del criterio real o de defensa.

\section{Aplicación en el tiempo ${ }^{59}$}

En la aplicación de la ley penal, en su dimensión temporal a los ilícitos electorales deben seguirse las pautas previstas en la parte general del Código Penal costarricense sobre el tema (artículos 11 a 15). Por regla de principio se juzgarán las conductas según las normas vigentes al momento de la comisión del hecho punible. ${ }^{60}$

Esa correspondencia entre la ocurrencia del evento y la ley penal regente para ese instante en gran medida es proyección de la irretroactividad de la norma punitiva como principio constitucional que informa el Derecho Penal. ${ }^{61} \mathrm{Sin}$ embargo el sistema costarricense es tributario de lo que Creus denomina "irretroactividad relativa", 62 pues el legislador admite hipótesis según las cuales es posible la aplicación de previsiones legales aprobadas con posterioridad a la acción reprochable; esos supuestos serán, básicamente, aquellos relativos a la retroactividad in mitius y la posibilidad de, a través del recurso de revisión solicitar readecuaciones o liquidaciones de pena cuando el tipo base de la condena ha sido modificado o derogado. este tema.

Según lo anterior es innecesario realizar mayores precisiones respecto de

\section{Sobre la prescripción}

En un sentido similar a lo expuesto en el apartado inmediato anterior los delitos electorales, al ser de conocimiento de la jurisdicción penal ordinaria (artículo 285 $\mathrm{CEc}$ ), están sujetos a las normas procesales y sustantivas (referentes a la TDD)

\footnotetext{
${ }^{59}$ Un desarrollo de dogmático de este tema y sus aplicaciones puede verse en CASTILLO (2008), pp. 192-224, t.I; y, en general, las fuentes enunciadas en la cita acerca de la "irretroactividad y la aplicación de la ley penal".

${ }^{60} \mathrm{El}$ "momento de la comisión" debe precisarse según lo prescribe el numeral 19 del Código Penal: CASTillo (2008), pp. 196-197.

${ }^{61}$ Sobre la relación entre irretroactividad y aplicación de la ley penal en el tiempo pueden consultarse, entre otros CREUS (1992), pp. 92-96; BACIGALUPO (1996), pp. 56 y ss.; ROXIN (1997), pp. 161-169; y, ZAFFARONI (1998), pp. 459 y ss.

${ }^{62}$ Creus (1992), p. 94
} 
Cambronero - Reflexiones sobre algunos contenidos de la justicia penal electoral ...

ordinarias. Empero existen discusiones generales en punto a este tema que, al incidir de manera directa en los ilícitos objeto de la investigación, conviene reseñar.

No pocas son las discusiones acerca de la "naturaleza" de la prescripción de la acción: la interrogante sobre si esas previsiones normativas son de contenido sustantivo o más bien son de carácter procesal ha sido tratada ampliamente en la doctrina. ${ }^{63}$ En Costa Rica, por ejemplo, esa veleidad se filtró en la legislación: hasta 1997 el legislador reguló la prescripción de la acción en el Código Penal (norma sustantiva por excelencia) y luego, con la entrada en vigencia del Código Procesal Penal (Ley n. ${ }^{\circ}$ 7594), las reglas generales para su definición, cómputo, interrupción y suspensión fueron previstas en esa norma adjetiva.

Esa discusión no es baladí. Allende de cuán persuasiva es una u otra postura lo realmente importante es cuál sentido de la prescripción ha llegado a posicionarse como paradigma dentro de los operadores jurídicos, pues de esto depende cómo se aplicará de hecho el citado instituto a los casos concretos. Así, en nuestro medio la doctrina imperante es la de entender la prescripción de la acción penal como un tema procesal.

Castillo respalda lo anterior indicando que "la prescripción de la acción penal no excluye ni lo injusto ni la culpabilidad del hecho", sino más bien comporta un impedimento para perseguir una conducta dañosa de un sujeto (manifestaciones con las cuales se está de acuerdo). Sin embargo el autor utiliza esa fundamentación para otorgar la etiqueta de "normas procesales" y, en razón de ello, justifica su aplicación directa sea la improcedencia de invocar la irretroactividad de la ley en los casos donde se agrava la penalidad de un tipo con el consecuente aumento en el plazo de prescripción. ${ }^{64}$

Ciertamente la prescripción de la acción supone un obstáculo de procedibilidad esto es una imposibilidad para que el órgano persecutor instaure $-\mathrm{O}$ continúe- un proceso penal en contra de un sujeto como "castigo" a la inercia punitiva. Desde esa inteligencia en efecto las normas relacionadas con este instituto tienen una marcada génesis procesal, empero ese linaje no supone per se un adecuado tratamiento del problema.

Sostener que una norma por ser procesal puede ser retroactiva -independientemente de las consecuencias reales para el imputado- es zafar del problema sin siquiera llegar a él. Al decirse que "la aplicación de la probibición de retroactividad de la [sic] leyes referentes a las penas y a los delitos, que se basa en la necesidad del ciudadano de saber a qué atenerse en el momento de actuar, no se puede, por consiguiente,

${ }^{63}$ Ver, además de CASTILLO (2008), t. I, pp. 222-223, las referencias que ese autor reseña en las notas 1027 a 1033.

${ }^{64}$ Castillo (2008), t. I, p. 223. 
transferirse al Derecho procesal penal y concretamente a las disposiciones sobre la prescripción de la acción penal' ${ }^{65}$ oculta inconsistencias no menores.

De acuerdo con los plazos del Código Procesal Penal costarricense los delitos prescriben en el extremo mayor de la penalidad indicada en el tipo siempre que esta no sea superior a diez años o inferior a tres años; la extinción de la acción penal por prescripción está íntimamente vinculada entonces a los extremos de la pena. De esa suerte si para la aplicación de la ley penal ha de tomarse en cuenta la vigente al momento de los hechos -tratándose del tipo y sus componentes- en una perspectiva armonizadora debería ocurrir lo mismo para la prescripción.

Véase que el argumento central para defender la irretroactividad en lo sustantivo es la certeza para el sujeto pero, de igual modo, podría esgrimirse para la norma procesal de prescripción. Si un sujeto decide asesinar a otro sabe a qué atenerse en cuanto a los años que, de resultar culpable puede purgar prisión y si siguiera una teoría pura del rational choice (como parece ser una de las premisas de la doctrina) tendría los elementos necesarios para aventurar su cálculo: dar muerte al peor enemigo vs los años en presidio por tal acción. Tratándose de la extinción de la acción penal por la causa en comentario vendría a ser un poco lo mismo: si se conocen el tiempo promedio de resolución de causas, efectividad del ente fiscal y se sabe del plazo de prescripción sería dable hacer una apuesta por la impunidad en razón del transcurso del tiempo: el sujeto comete el delito pues tiene elementos para barruntar una posible prescripción de la causa.

Contrario a esa certeza en las dos vías (sustantiva y procesal) se opta por fragmentar el sistema y en razón (jo sin razón!) de una etiqueta específica de norma "adjetiva" se valida la existencia de hipótesis que siendo escasamente probables dan paso a escenarios contrarios a otros consensos del derecho penal democrático como la seguridad jurídica o la interpretación favorable al imputado. Para ilustrar piénsese en una situación de rezago en la persecución de cierto tipo de delitos cuya penalidad superior sean los cinco años de prisión; preocupados por ello, los diputados modifican el tipo penal para que el extremo mayor de la pena se ubique en los nueve años y así el plazo de prescripción se ve extendido para los casos en trámite.

El cuadro fáctico propuesto se utiliza para visibilizar un posible escenario neopunitivista, pero -a la inversa- también hay cabida para la manipulación: un grupo considerable de importantes políticos podrían haber cometido una clase de ilícitos sancionados con pena privativa de libertad de hasta doce años de prisión, sin embargo una mayoría parlamentaria introduce modificaciones a la ley penal para reducir el extremo superior de la penalidad a cuatro años con lo que dramáticamente se habrá reducido también el plazo de prescripción de la acción penal.

65 Castillo (2008), p. 223. 
Cambronero - Reflexiones sobre algunos contenidos de la justicia penal electoral ...

Como puede observarse no solo desde una lógica de uniformidad para el sistema punitivo - con incidencia sobre la tan mentada certeza jurídica para el imputado-, sino desde la eventual apertura de espacios para la manipulación institucional resulta poco oportuno aplicar irreflexivamente recetas. En efecto las normas procesales son en su contenido distintas a las sustantivas, pero esto lejos de servir para la legitimar el uso de ecuaciones debe ser aliciente para la reflexión con base en un marco axiológico concreto: ¿se corresponde la retroactividad de la prescripción con un modelo democrático de justicia penal?

Luego de la anterior digresión cuyo planteamiento como se indicó tiene relación con el tema en estudio conviene sintetizar: en los tipos penales electorales, como en el resto de delitos, el plazo de prescripción será el indicado en el Código Procesal Penal. Por regla de principio se extinguirá la acción penal una vez transcurrido un plazo igual al extremo mayor de la pena prevista siempre y cuando este se encuentre entre los tres y los diez años; esto variará si en el caso concreto se suscitan causales de suspensión o interrupción del plazo.

Por último, si bien las "faltas electorales" (numerales 286 a 302 del CEc) exceden el objeto del presente estudio (por no comportar materia penal en sentido estricto) vale indicar que no se previó en la legislación electoral el plazo de prescripción de donde resulta oportuno un ejercicio hermenéutico del Juez Electoral $^{66}$ en el que se fijen tales reglas. De hecho, así ocurrió.

El TSE, por sentencia n. ${ }^{\circ}$ 6229-E3-2015 de las 15:45 horas del 8 de octubre de 2015 estableció que tratándose de las faltas electorales el plazo de prescripción "es el término decenal establecido por el legislador en el artículo 868 del Código Civil; y que, además, su cómputo se inicia desde el momento en que la administración electoral tenga pleno conocimiento de los hechos que podrían configurar la falta electoral" (el resaltado corresponde al original).

Si bien el Juez Electoral -en la referida sentencia- fundamentó su postura acerca del porqué no resultan aplicables las reglas de la normativa procesal penal a tales ilícitos, ${ }^{67}$ lo cierto es que, según nuestro criterio, debió tomarse en consideración el carácter sancionatorio (y, si se quiere, represivo) de esas figuras.

\footnotetext{
66 En ejercicio de su competencia exclusiva y obligatoria para interpretar las normas constitucionales y legales en materia electoral (artículo 102.3 de la Constitución Política costarricense).

${ }^{67}$ En esencia, porque en el catálogo de fuentes del Derecho Electoral -previsto en el numeral 3 del CEc- no preveía la rama penal.
} 
En ese sentido el plazo de prescripción de las faltas pudo homologarse con el plazo previsto para las contravenciones $(2 \text { años })^{68}$ o si se consideran estas figuras más afines a las sanciones administrativas pudieron tomarse parámetros de leyes que sancionan conductas con un número determinado de salarios base (como ocurre en el CEc) dentro de las que está la Ley n 9078 , "Ley de Tránsito", que señala: "la acción administrativa prescribe en dos años, computados desde el levantamiento de la boleta de citación" (ordinal 190). ${ }^{69}$ Nótese que los plazos de la normativa civil se encuentran fraguados a la luz de las relaciones jurídicas propias de esa rama del Derecho: contratos, derechos y deberes suscitados entre los particulares, pero en lo penal-electoral se está en la típica relación sujeto (s) frente al poder punitivo del Estado.

\section{La (ir)responsabilidad de las personas jurídicas y los partidos políticos}

La doctrina tradicional ${ }^{70}$ ha excluido ad initio la posibilidad de que las personas jurídicas puedan tener responsabilidad penal, pues básicamente, carecen de capacidad de acción. Sobre esa línea Creus señala: "El concepto de acción precedentemente expuesto proviene de la teoría general del hecho ilícito del que se responde subjetivamente, que sólo puede ser conducta y, en cuanto tal, conducta de un autor, lo cual indica que es inútil ponerse a meditar en la punibilidad de las personas jurídicas, que jamás pueden aparecer como un autor que asume conductas.". ${ }^{71}$ En idéntico sentido, Zaffaroni sostiene: "Entendemos que en el derecho penal "estricto sensu", las personas jurídicas no tienen capacidad de conducta, porque el delito según surge de nuestra ley es una manifestación individual bumana". 72

Para el caso costarricense, el panorama no es distinto. Castillo resume tal postura al indicar: "En nuestro Derecho penal la responsabilidad penal de las personas jurídicas no existe, pues ellas no son capaces de acción en materia penal y tampoco son capaces de tener dolo o culpa o de tener culpabilidad.,$" 3$

Sin embargo de un tiempo a esta parte se ha suscitado una discusión tendiente al replanteamiento del clásico aforismo romano societas delinquere non potest. En efecto la aparición de fenómenos criminales relacionados con sociedades

\footnotetext{
${ }^{68}$ El artículo 31 inciso b) del Código Procesal Penal señala: Si no se ha iniciado la persecución penal, la acción prescribirá: [...] b) A los dos años, en los delitos sancionables sólo con penas no privativas de libertad y en las faltas o contravenciones.

${ }^{69}$ Como se aprecia, ambos plazos corresponden a dos años.

${ }^{70}$ Aparte de los autores que se citan, se excluye la capacidad de acción de las personas jurídicas en BaCigalupo (1994), p. 57, MuÑoz CONDE (1984), pp. 9-11 y ROXIN (1997), pp. 258-259, entre otros.

${ }^{71}$ CREUS (1992), p. 160.

72 ZAFFARONI (1998), t. III, p. 57.

${ }^{73}$ Castillo (2008), p. 317
} 
Cambronero - Reflexiones sobre algunos contenidos de la justicia penal electoral ...

anónimas (delitos tributarios y fiscales), así como delincuencia de grupo han llevado a profundizar en el tema de si es relevante para el Derecho Penal perseguir a las personas jurídicas.

Zúñiga por ejemplo señala: "La construcción de un modelo de responsabilidad penal de la persona jurídica paralelo a la responsabilidad individual, permite distinguir cuando un ilícito es cometido por una persona física que se sirve de una persona jurídica y cuando se trata de un ilícito de organización, un tipo de criminalidad de grupo". $74 .{ }_{-}^{75}$

Para fundamentar una construcción de un modelo de responsabilidad penal a la persona jurídica a partir de una deconstrucción del sistema existente, esa autora repasa el paradigma sancionatorio actual que permite la individualización de la responsabilidad cuando los hechos son llevados a cabo por una persona moral. Puntualmente se diferencia entre: a) la imputación de los órganos y representantes; y, b) la imputación al titular de la empresa.

En el primero de lo casos la construcción normativa está dirigida a "seleccionar a uno o varias personas físicas, órganos o representantes de la empresa como «chivos expiatorios", con el fin de no dejar el hecho impune y tranquilizar a las victimas así como a la ciudadania que reclama justicia". ${ }^{76}$ Así uno de los principales cuestionamientos a la formulación -y que mostraría su insuficiencia como respuesta punitiva- es la criminalización de sujetos con un poder de decisión real bajo y que a la postre son fungibles dentro de la organización.

Por otro lado imputar al titular de la empresa supone reconocerle responsabilidad en las operaciones de esta, o sea le asiste un deber de vigilancia acerca de la corrección del accionar de la organización. Específicamente, el Directivo se encuentra una posición de garante frente a las actividades de la empresa.

No obstante, ese último aspecto -posición de garante- es uno de los principales óbices: "no existe acuerdo en determinar quiénes y con qué límites tienen posición de garante de las actividades de terceros en la empresa, lo cual implican bases dogmáticas poco consensuadas". ${ }^{77}$

\footnotetext{
${ }^{74}$ ZÚÑ̃IGA (2004).

${ }^{75}$ ROXIN (1997), pese a ceñirse a la incapacidad de acción de las personas jurídicas, no desconoce los debates que, sobre este tema, se han suscitado. Para ilustrar, este penalista precisa: hay defensores de castigar directamente a las personas colectivas (...) Una parte de éstos sostiene que se puede tratar a las personas colectivas como a las personas reales (Hirsch), y se intenta superar su falta de capacidad de acción mediante la construcción de que las personas colectivas actuan a través de sus órganos, mientras que el reproche de culpabilidad por el fallo de aquéllos se les debe imputar directamente a las personas colectivas.

76 ZÚÑ̃IGA (2004), p. 280.

${ }^{77}$ Ibid., p. 283.
} 
Ahora bien tratándose de los delitos electorales, particularmente los relacionados con la recepción de contribuciones privadas ilegales y los relativos a las tesorerías de los partidos políticos, puede afirmarse que se da una mezcla de ambos modelos de imputación: los tres primeros incisos del numeral 275 CEc tienen como sujeto activo al miembro del comité ejecutivo superior; siendo este el órgano ejecutivo de mayor rango en lo interno de la estructura partidaria. Ciertamente la máxima autoridad de una agrupación política es su asamblea superior (nacional, provincial o cantonal, según la escala), pudiéndose equiparar esta -mutatis mutandis- con el grupo de accionistas de una empresa, ${ }^{78}$ pero pese a ello la titularidad (y un grado importante de autoridad) es reconocida a los integrantes de ese comité ejecutivo.

De acuerdo con lo anterior, manteniendo la conceptualización de Zúñiga puede decirse que el tipo penal está construido para responsabilizar a los "directivos" por el correcto accionar del partido político en asuntos financieros (modelo b), mas también es cierto que los miembros del citado comité son los representantes de la agrupación "quienes son en definitiva sustituibles, por lo que la «actitud criminal del grupo» o las conductas riesgosas para bienes jurídicos pueden mantenerse buscando otro representante" (modelo a). ${ }^{79}$

Las agrupaciones políticas presentan estructuras de poder formales (diversas instancias de representación previstas normativamente), pero además suponen la existencia de grupos con influencia simbólica sobre las dinámicas internas. Ese dualismo permite imaginar escenarios como el descrito en el párrafo anterior a través de ejemplos como el siguiente: el día de una elección un grupo económico decide apoyar a un partido político a través de la donación de alimentos para los fiscales y miembros de JRV, el comité ejecutivo desconoce de tal situación. La "alianza" ha sido producto de un acuerdo entre los "patrocinadores" y el comando de campaña del candidato quienes son de una tendencia interna diversa a la de la estructura formal; por ende, ante una eventual persecución penal, los afectados serán quienes ostentan los cargos de representación. ${ }^{80}$

Frente a tales circunstancias vale cuestionarse si esas previsiones penales resultan de pertinentes para disuadir las conductas indeseadas. ${ }^{81}$ Por una parte se puede argumentar en favor de las actuales reglas, explicitando que se trata de un diseño omnicomprensivo: ${ }^{82}$ hay una tipificación penal para los representantes

\footnotetext{
${ }^{78}$ Es claro que existe una diferencia de origen entre una empresa y un partido político, en tanto este último es una asociación voluntaria de ciudadanos sin fines de lucro; mas para efectos de la explicación cierto es que la asamblea superior tiene un paralelismo con los accionistas: ambos órganos son los cuerpos deliberativos máximos.

79 ZÚÑ̃Ga (2004).

${ }^{80}$ Chivos expiatorios en los términos de ZúÑIGA (2004).

${ }^{81}$ Ver la norma en su dimensión de tecnología social.

82 En este aspecto el sistema costarricense podría encuadrar en la siguiente descripción de ROXIN (1997), p. 259: "Dado que existe la necesidad de volver a privar a la persona jurídica de los beneficios que ha
} 
Cambronero - Reflexiones sobre algunos contenidos de la justicia penal electoral ...

partidarios responsables de velar por el adecuado financiamiento cuando no cumplen con sus obligaciones o admiten contribuciones prohibidas; y, simultáneamente, se previeron faltas electorales tendientes a imponer a la agrupación política - en su carácter de persona jurídica- multas por recibo de contribuciones irregulares y por el incorrecto control de aportes privados (artículos 287 y 288 del CEc).

En otra vertiente es viable afirmar una insuficiencia acerca de las sanciones por imponer directamente a las agrupaciones políticas. Roxin resume que: "Un sector [...] propone un "modelo de medidas de seguridad" que sirva "como base legitimadora de sanciones complejas, que unan elementos represivos y preventivos, para las personas jurídicas"”." 83 Ese modelo, en virtud de la previsión del artículo 245 del Código Penal, es observado parcialmente en Costa Rica.

Esa línea argumentativa es aceptada por Castillo al sostener: "puesto que las medidas de seguridad se imponen cuando no hay culpabilidad pero si peligrosidad, es posible imponer como medida de seguridad el cierre, por un tiempo determinado, del establecimiento de la persona jurídica en cuyo nombre delinquió su administrador, gerente, su representante o su dependiente sin violar el principio de culpabilidad. ${ }^{, 84}$

De esa suerte, en el caso costarricense podría pensarse en complementar el sistema de sanciones previendo medidas de seguridad en contra de las agrupaciones políticas cuyos representantes hayan cometido algún delito electoral. Así, pueden ensayarse alternativas al cierre como la imposibilidad de presentar ciertas nóminas de candidatos en la elección inmediata siguiente al momento en el que se afirme la responsabilidad. En todo caso estas variaciones dependerán de la política criminal que ideológicamente defina el parlamento.

En suma, hasta tanto no opere un cambio normativo en el sistema jurídico costarricense no son considerados acciones -en términos penales- los actos desplegados por personas jurídicas (incluidos los partidos políticos).

\section{Reflexión de cierre}

La realidad es amplia y compleja, va más allá de la parcial visión que de ella realiza el entramado legal. En definitiva la persecución de eventuales delitos electorales

obtenido mediante los delitos de sus órganos y que también en otros aspectos se considera que una actuación penal sobre el patrimonio de la persona jurídica es frecuentemente más eficaz que la exigencia de responsabilidad a sus órganos, no es inusual la pena para las asociaciones en el Derecho extranjero, sobre todo en Inglaterra y en EE.UU.”. Discusión aparte es si las faltas electorales tienen un carácter penal (una suerte de contravenciones) o más bien se asemejan a una falta administrativa.

${ }^{83}$ ROXIN (1997), p. 259.

${ }^{84}$ CASTILlO (2008), t. I, p. 318. 
requiere de un posicionamiento particular, en breve: la delincuencia electoral presenta rasgos no convencionales que justifican la aplicación diferenciada de los componentes de la Teoría del Delito, tanto en la creación de los tipos penales que criminalizan las conductas, como en las fases de comprobación de tales elementos conceptuales frente a casos concretos.

Por ello si bien los locutores del derecho sancionatorio podrían, por ejemplo, entender más fácilmente -como acto lesivo- los ilícitos por financiamiento espurio de campañas electorales (en razón de su proximidad o parecido con sus representaciones mentales de las categorías criminales tradicionales, v.gr. la estafa), aún en tales casos debe hacerse una lectura de la dinámica con una perspectiva específica.

Precisamente esa especificidad fenoménica llama a un estudio del objeto desde nuevos ángulos, obliga a una propuesta de nuevas guías orientadoras como las que se han pretendido explicar en las que la dogmática jurídico-penal se conjuga con los elementos socio-políticos del sistema electoral.

En América Latina alcanzar la pureza del sufragio ha sido una ardua tarea, varias "olas democratizadoras" dan testimonio de ello. Luego de resolver los problemas de la Democracia procesal resulta oportuno blindar los sistemas políticos con instrumentos que permitan el adecuado juzgamiento de conductas que, a la postre, minan la confianza ciudadana en las instituciones. En esa tarea una adecuada comprensión de la Justicia Penal Electoral resulta trascendental. 
Cambronero - Reflexiones sobre algunos contenidos de la justicia penal electoral ...

\section{BIBLIOGRAFÍA}

* Acosta, Miguel y López, Eduardo (1990): Delitos Especiales. Porrúa, México.

* Ahuntzi, Hilario (2002): "Sujetos de Delitos Electorales", en: Revista Mexicana de Justicia (3), México.

* Albert, Hans (2007) La Ciencia del Derecho como Ciencia Real (Pres., trad. y ns.: Minor E. Salas), Fontamara, México.

* AltÉs, Miguel Ángel (1999): "El delito Electoral”, Anuario de Derecho Parlamentario n 8 , Ed. Corts Valencianes.

* Bacigalupo, Enrique (1994): Lineamientos de la Teoría del Delito, Editorial Hammurabi S.R.L., Buenos Aires.

* Barrios, Boris (2009): La Justicia Penal Electoral. Conferencia pronunciada el 2 de octubre en la ciudad de Santo Domingo, República Dominicana, en línea: https://borisbarriosgonzalez.files.wordpress.com/2011/08/la-investigacic3b3n-penalelectoral-boris-barrios-gonzc3a1lez.pdf

* Betanzos, Eber (2012): "Delitos electorales y procuración de justicia penal electoral", en: Justicia Electoral, Revista del Tribunal Electoral del Poder Judicial de la Federación Cuarta época, vol. 1, n. ${ }^{\circ} 10$ (julio-diciembre), Tribunal Electoral del Poder Judicial de la Federación, México.

* Brenes, Luis Diego (2013): "El Rol político del Juez Electoral”, Tribunal Supremo de Elecciones, Instituto de Formación y Estudios en Democracia, San José.

(2002): Jurisdicción constitucional electoral. Tesis de Licenciatura en Derecho, Facultad de Derecho, Universidad de Costa Rica.

* Cambronero, Andrei y Mora, Iván (2015): El control de constitucionalidad de las normas electorales, Editorial IFED-TSE, Costa Rica.

(2011): "Simplismo jurídico: algunas manifestaciones en la jurisdicción", en: Revista IUS DOCTRINA, Facultad de Derecho, Universidad de Costa Rica.

* Casas, Kevin y Zovatto, Daniel (2011): "Para llegar a tiempo: apuntes sobre la regulación del financiamiento político en América Latina", en Revista de Derecho Electoral, (12) en línea: http://nuso.org/media/articles/downloads/3672_1.pdf

* Castillo, Francisco (2008): Derecho Penal Parte General. 3 Tomos, Editorial Jurídica Continental, San José, Costa Rica.

* Creus, Carlos (1992): Derecho Penal parte general (3era edición), Astrea, Buenos Aires, Argentina.

* CruZ, María José (2013): “La protección penal del Derecho al sufragio", en Revista Electrónica de Ciencia Penal y Criminología, en línea: http://criminet.ugr.es/recpc/15/recpc15-13.pdf

* Código Electoral. República de Costa Rica. Ley n. 8765 del 19 de agosto del 2009.

* Código Electoral. República de Costa Rica. Ley n. 1536 del 10 de diciembre de 1952.

* Código Penal. República de Costa Rica. Ley n. ${ }^{\circ} 4573$ del 4 de mayo de 1970.

* Código Procesal Penal. República de Costa Rica. Ley n. 7594 del 10 de abril de 1996.

* Constitución Política de la República de Costa Rica (2005). San José: Editorial Investigaciones Jurídicas.

* De la Calle, Humberto (2011): "La relevancia de la transparencia en la rendición de cuentas, y sus efectos sobre la legitimidad de los partidos políticos", en Revista de Derecho Electoral, (11), en línea: http://www.tse.go.cr/revista/art/11/calle_lombana.pdf

* Díaz-Santana, Héctor (2013): "Reflexiones sobre los delitos electorales y la FEPADE a partir de la alternancia política (2000 al 2012)", en: Revista Mexicana de Derecho Electoral, n. ${ }^{\circ}$ 3. México: UNAM, en línea: http://revistas.juridicas.unam.mx/index.php/derechoelectoral/article/view/10005/12033 
* DíAz, José (2010): “Génesis de las reglas electorales en Costa Rica: desde la colonia hasta 1838", en Revista de Derecho Electoral, (10), en línea: http://www.tse.go.cr/revista/art/10/diaz_gonzalez.pdf

* Instituto Interamericano de Derechos Humanos (2000): Diccionario electoral, Tomos I y II, San José.

* FernÁndeZ, Héctor (2006): "El proceso electoral", en Revista de Derecho Electoral, (1), en línea: http://www.tse.go.cr/revista/art/1/fernandez.pdf

* Fiscalía General de la República de Costa Rica (2013): Circular n. 01-PPP-2013.

* Fundación Konrad Adenauer (2010): "Seguridad y Crimen organizado transnacional: una propuesta de acción para Centroamérica”. Paper n. ${ }^{\circ} 11$.

* Gálvez, Luis y Rubio, Pedro (2007): "El régimen de votación de las personas especialmente vulnerables y sus garantías, en particular la penal”, en: Anales de Derecho (25), Universidad de Murcia, España.

* Haba, Enrique Pedro (2012): Metodología (Realista) del Derecho. 3 Tomos, Instituto de Investigaciones Jurídicas \& Editorial Universidad de Costa Rica, San José, Costa Rica.

* Instituto Interamericano de Derechos Humanos (2002): Diccionario Electoral. Vol. 2, Tomos I y II, Editorial IIDH, Costa Rica.

* Instituto Interamericano de Derechos Humanos (1998): Tratado de derecho electoral comparado de América Latina.

* Kunn, Thomas (1989): Conmensurabilidad, Comparatibilidady comunicabilidad, Paidós, España.

* LehoucQ, Fabrice (1993): "Política, Democracia y Guerra Civil en Costa Rica", en Revista Reflexiones, (14). Facultad de Ciencias Sociales, Universidad de Costa Rica.

* Ley de Tránsito. República de Costa Rica. Ley n. ${ }^{\circ} 9078$ del 4 de octubre de 2012.

* Ley de Regulación del Referéndum. República de Costa Rica. Ley n. 8492 del 9 de marzo de 2006.

* Martínez, Eduardo (2003): "Derecho penal electoral: un planteamiento de derecho penal especial y criminología crítica”, en Revista Mexicana de Justicia. México, DF. n. ${ }^{\circ} 5$.

* Molina, Iván y LeHOuCQ, Fabrice (1999): Umas de lo inesperado: fraude electoral y lucha politica en Costa Rica: 1901-1948, Editorial de la Universidad de Costa Rica, San José, Costa Rica.

* Mora, Carolina (2010): "La creación del Tribunal Supremo de Elecciones de Costa Rica en 1949: sus antecedentes y significado en la institucionalidad nacional", en Revista de Derecho Electoral, (9), en línea: https://es.scribd.com/doc/300231008/La-Creacion-DelTribunal-Supremo-de-Elecciones-de-Costa

* Muñoz-Conde, Francisco (1984): Teoría General del Delito, Editorial TEMIS, Bogotá.

* ORTS, Enrique (1977): “Consideraciones críticas en torno a los tipos penales del Real Decreto-Ley 20/1977, de 18 de marzo, sobre normas electorales", en Cuadernos de Política Criminal, n. 3.

* Plascencia, Raúl (2010): "Delitos contra la democracia electoral", en Temas de Derecho Penal, Seguridad Pública y Criminalística, Universidad Autónoma de México, Serie Doctrina Jurídica (264).

* Reglamento para el ejercicio del voto en el extranjero (2013): Decreto n. ${ }^{\circ}$ 4-2013 del Tribunal Supremo Elecciones.

* Roxin, Claus (1997): Derecho Penal. Parte General, Civitas, Madrid.

* Roxin, Claus/Jakobs, Günther/Schünemann, Brend/Frisch, Wolfgang/KöHLER, Michael (2000): Sobre el estado de la teoría del delito, Civitas, Madrid.

* Salas, Minor (2013): Yo me engaño, tú te engañas, el se..., $2^{\text {da }}$ edición, ISOLMA, San José.

* Sobrado, Luis (2012): "El deslinde competencial entre el Tribunal Supremo de Elecciones y la Sala Constitucional: una historia inconclusa en cuatro capítulos", en Revista 
Cambronero - Reflexiones sobre algunos contenidos de la justicia penal electoral ...

de Derecho Electoral, (12), en línea:

http://www.tse.go.cr/revista/art/12/sobrado_gonzalez.pdf

(2011): "La financiación de los partidos políticos en Costa Rica", en Evaluando la calidad de la democracia: guía práctica. IDEA Internacional, en línea: http://www.tse.go.cr/revista/art/8/Sobrado_Gonzalez.pdf

(2005): La justicia electoral en Costa Rica, Investigaciones Jurídicas, San José.

* Tribunal Supremo de Elecciones (TSE) República de Costa Rica (2015): Resolución n. ${ }^{\circ}$ 6229-E3-2015 de las 15:45 horas del 8 de octubre de 2015.

* WitTgenstein, Ludwig (2012): Tractatus lógico-philosophicus (trad. Routledge \& Kenan), Alianza Editorial S.A., Madrid.

(1999): Investigaciones filosóficas (trad. Alonso Garcia y Ulises Moulines), Ediciones Altaya S.A., España.

* Zaffaroni, Eugenio (1998): Tratado de Derecho Penal Parte General, Ediar S.A., Buenos Aires, Argentina.

* Zamora, Arturo (2003): Delitos Electorales, Ángel Editor, México.

* ZúNiga, Laura (2004): "La cuestión de la responsabilidad penal de las personas jurídicas, un punto y seguido", en: Nuevos retos del derecho penal en la era de la globalización, Tirant lo Blanch, Valencia. 